\title{
RECICLAGEM DE REJEITOS DA CONSTRUÇÃO CIVIL PARA USO EM ARGAMASSAS DE BAIXO CUSTO
}

\author{
Luciana Viana Amorim¹, Ana Silvia Gomes Pereira², Gelmires de Araújo Neves \\ \& Heber Carlos Ferreira ${ }^{4}$
}

\begin{abstract}
RESUMO
Com o objetivo de se obter aglomerantes pozolânicos a partir da reciclagem de rejeitos da construção civil, foram estudadas duas amostras de entulho, uma de resíduo de cerâmica vermelha e uma pozolana artificial, e duas amostras de cal. As amostras foram caracterizadas através de análise química, análise térmica diferencial, difração de raios-X, área específica e determinação da atividade pozolânica. As amostras de entulho e resíduo cerâmico foram moídas em moinho de bolas por 90 min e a de pozolana artificial em moinho de discos. Foram preparadas argamassas alternativas, no traço 1:3 e, como aglomerante, cal pozolânica, em composições $30-70 \%, 40-60 \%$ e 50-50\% de cal e pozolana. Os corpos de prova foram curados por períodos de 7, 28 e 60 dias e submetidos a ensaios de resistência a compressão simples, cujos resultados mostram que a reciclagem de rejeitos é promissora, podendo gerar elementos construtivos de baixo custo e que seu uso implica na preservação do meio ambiente e na melhoria da qualidade de vida da população em geral.
\end{abstract}

Palavras-chave: reciclagem, entulhos, meio ambiente, argamassa alternativa

\section{RECYCLING OF CIVIL CONSTRUCTION WASTES FOR USE IN LOW COST MORTARS}

\begin{abstract}
With the objective of obtaining lime-pozzolana cements from the recycling of civil construction waste, four samples consisting of ceramic residue (bricks and tiles), artificial pozzolana and two samples of hydrated lime were studied. All samples were characterized by chemical analysis, thermal differential analysis, X-ray diffraction, specific area and activity pozzolanic. The waste samples and ceramic residues were ground in a ball mill for $90 \mathrm{~min}$ and that of artificial pozzolana in a disk mill. The alternative mortars were prepared using as aglomerate lime pozzolanic cement in proportion of 30-70, 40-60 and 50-50\% of lime and pozzolana, respectively. The specimens were cured for periods of 7, 28 and 60 days and submitted to the RCS trials. The results obtained show that the recycling of civil construction waste is a promising technique which may generate low cost elements, destined for civil works and its use implies in the preservation of the environment and in the improvement of the quality of life of the population in general.
\end{abstract}

Key words: recycling, waste, environment, alternative mortars

\footnotetext{
${ }^{1}$ Eng. de Materiais, Aluna do Curso de Pós-Graduação em Eng. Química, Universidade Fderal da Paraíba, Av. Aprígio Veloso 882, Bodocongó, CEP 58109 - 970, Campina Grande, PB. Fone: (083)310 1183, Fax: (083)310 1180, E-mail: luciana@ deq.ufpb.br

${ }^{2}$ Aluna do Curso de Graduação em Engenharia de Materiais, Universidade Federal da Paraíba

${ }^{3}$ Professor, M.Sc., Departamento de Engenharia de Materiais, Universidade Federal da Paraíba. E-mail: gelmires@ dema.ufpb.br

${ }^{4}$ Professor, Doutor, Universidade Federal da Paraíba. E-mail: heber@ dema.ufpb.br
} 


\section{INTRODUÇÃO}

Desde a antigüidade, o homem sempre dependeu das rochas, inicialmente usadas como abrigo e, depois, como arma e ferramenta. Hoje, mesmo com toda a sofisticação e tecnologia de que dispomos, é indiscutível a nossa dependência aos recursos minerais. Apesar disto, o mundo atravessa graves problemas de ordem ecológica, devido ao desmatamento e às queimadas de florestas, à emissão excessiva de gases poluentes, à poluição das águas dos rios e mares e aos graves problemas urbanos causados pelo lixo doméstico, industrial e hospitalar, proveniente de entulhos de demolições e obras civis, entre muitos outros.

O lixo oriundo de entulhos da construção civil, embora não seja o lixo mais incômodo, sob o ponto de vista da toxidade, assusta pelo seu volume crescente e requer medidas imediatas; ele é, muitas vezes, utilizado na recuperação de áreas alagadas, para aterros e reaterros ou, então, simplesmente lançado, de maneira aleatória e irregular, na beira de estradas, cursos d'água ou antigas cavas, quando não lançados em aterros sanitários. Porém o problema reside, ainda, na escassez de áreas adequadas para a sua deposição que, com o crescimento metropolitano, vem-se tornando cada vez mais remotas; por outro lado, o entulho pode ser reciclado, gerando elementos construtivos. Nos Estados Unidos, seu aproveitamento é realizado há mais de 30 anos, para produzir agregados artificiais; enquanto na Europa se trata de uma atitude cultural, a Holanda, com mais de 40 usinas de reciclagem de entulho, recicla $70 \%$ dos resíduos e a Alemanha, 30\% (Coelho \& Chaves, 1998). No Brasil, a necessidade da reciclagem decorre do crescente déficit habitacional, além dos motivos ecológicos existindo, hoje, oito unidades de reciclagem, das quais duas em Belo Horizonte, uma em Ribeirão Preto, São José dos Campos, Londrina, Piracicaba, Muriaé e a usina de Itatinga, em São Paulo, instalada em 1991 que, segundo dados da época, podia reciclar 50\% do material que a ela chegava. Em 1992, esta usina apresentava produção de 500 t diárias de agregado (pedras, pedriscos e areia) com custos $80 \%$ menores que os de mercado (Villari, 1992). Em 1993, a prefeitura de São Paulo construiu um alojamento de $190 \mathrm{~m}^{2}$ com cerca de 4.000 blocos de concreto, feitos com entulho processado; decorridos cinco anos da construção, o prédio encontra-se ainda em excelentes condições. O custo de produção relacionado a esses blocos foi $70 \%$ inferior ao dos convencionais (Coelho \& Chaves, 1998).

O entulho de construção civil reciclado é, hoje, utilizado como agregado na produção de argamassas alternativas, que apresentam propriedades comparáveis e mesmo superiores àquelas apresentadas pelas argamassas convencionais (Cincotto, 1983; Pinto, 1997; Patrício et al., 1997; Levy \& Helene, 1995; Levy et al., 1997 e Silva et al., 1997); contudo, sendo o entulho composto principalmente de argamassas endurecidas e materiais cerâmicos (tijolos e telhas) quando moído se transforma em um material pulverulento, capaz de reagir com cal e, desta forma, obter um aglomerante hidráulico alternativo, nobre, também chamado cal pozolânica, utilizado nas civilizações romana e grega, antes da descoberta do cimento Portland.

O presente trabalho foi desenvolvido com o objetivo de se reciclar entulho e resíduo cerâmico da construção civil, visando à obtenção de agentes aglomerantes, com cal hidratada, para uso no preparo de argamassas alternativas de baixo custo.

\section{MATERIAL E MÉTODOS}

Os materiais estudados neste trabalho foram duas amostras de cal hidratada e quatro amostras de material pozolânico. A cal hidratada foi: cal Carbomil, proveniente de Fortaleza, fabricada no Município de Limoeiro do Norte, CE, e cal Megaó, oriunda de Recife, PE, fabricada pela Indústria Fazenda Megaó de Cima - Indústria e Comércio Megaó Ltda. As amostras de material pozolânico foram: duas de entulho de construção civil, uma de resíduo cerâmico e uma amostra de pozolana artificial denominadas como Entulho 1, amostra de entulho de construção civil, proveniente da demolição de uma casa residencial construída há 60 anos, localizada na Rua Desembargador Trindade, centro, Campina Grande, PB; Entulho 2, amostra de entulho proveniente da demolição de parte de uma das torres da Igreja Nossa Senhora da Conceição, Catedral, construída há 248 anos, localizada na Avenida Floriano Peixoto, Centro, Campina Grande, PB; Mistura, amostra de resíduo cerâmico, originado de uma mistura composta por $50 \%$ de tijolos furados e 50\% de telhas, utilizados em construções e adquiridos no comércio de Campina Grande, PB; Pozolana, amostra de pozolana artificial, produzida pela Itapessoca Agro Industrial S.A., localizada na Ilha de Itapessoca, no Município de Goiana, PE. Esta pozolana é obtida por tratamento térmico, a temperatura em torno de $700{ }^{\circ} \mathrm{C}$, a partir de uma argila caulinítica, de origem sedimentar, na Formação Barreiras, PE. Foi utilizada areia normal obtida por peneiração segundo a Norma NBR - 7214 (ABNT, 1982) a partir de areias normalmente utilizadas em construção civil e oriundas do Rio Paraíba do Norte, PB, e água potável, fornecida pela CAGEPA - Companhia de Água e Esgotos do Estado da Paraíba, para o sistema de abastecimento da cidade de Campina Grande, PB.

A parte experimental empregada para o desenvolvimento deste estudo segue as etapas descritas abaixo:

Preparação das Amostras: As amostras Entulho 1, Entulho $2 \mathrm{e}$ Mistura, foram submetidas ao processo de trituração, em britador de mandíbulas, e peneiradas em peneira $\mathrm{ABNT} \mathrm{n}^{\circ} 4$ (4,76 mm). Após esta etapa, elas foram acondicionadas em sacos plásticos de $50 \mathrm{~kg}$ e etiquetadas de forma a permitir sua identificação. A amostra Pozolana não passou por nenhum beneficiamento (trituração ou peneiração) uma vez que foi enviada ao laboratório com granulometria ideal para o estudo.

Moagem: As amostras Entulho 1, Entulho 2 e Mistura, foram secas em estufa a $110^{\circ} \mathrm{C}$, até massa constante e, em seguida, moídas em moinho de bolas (Singer \& Singer, 1971) durante 90 min. A amostra Pozolana foi moída em moinho de disco, com abertura entre os discos de $0,1 \mathrm{~mm}$.

Para os ensaios de caracterização mineralógica (análise química, análise térmica diferencial e difração de raios-X) as amostras de material pozolânico foram passadas em peneira $\mathrm{ABNT} \mathrm{n}^{0} 200(0,074 \mathrm{~mm})$ e as amostras de cal foram utilizadas na forma original.

Análise Química: Realizada segundo métodos do Laboratório de Análise Minerais do CCT/PRAI/UFPB, LAM - CG (Anônimo, 1994).

Análise Térmica Diferencial (ATD): As análises foram realizadas em equipamento BP Engenharia modelo RB12, operando a $12,5^{\circ} \mathrm{C} \mathrm{min}{ }^{-1}$. A temperatura máxima foi de $1000{ }^{\circ} \mathrm{C}$ 
e o padrão utilizado foi o óxido de alumínio $\left(\mathrm{Al}_{2} \mathrm{O}_{3}\right)$ calcinado, passado em peneira $\mathrm{ABNT} \mathrm{n}^{\circ} 200(0,074 \mathrm{~mm})$.

Difração de Raios-X: As análises foram realizadas em equipamento Phillips, modelo X'Pert MPD, operando com radiação K-alfa de cobre, $40 \mathrm{kV}$ e $40 \mathrm{~mA}$, com varredura entre $2 \theta$ $\left(2^{\circ}\right)$ e $2 \theta\left(90^{\circ}\right)$.

Área Específica: As amostras de cal e material pozolânico foram secas a $110^{\circ} \mathrm{C}$, até massa constante, e esfriadas em dessecador, até a realização dos ensaios; as áreas específicas foram determinadas pelo método do permeâmetro de Blaine e expressas em $\mathrm{m}^{2} \mathrm{~g}^{-1}$, segundo a Norma NBR-7224 (ABNT, 1994) para cuja aplicação utilizou-se uma amostra-padrão de cimento, fornecida pela Associação Brasileira de Cimento Portland - ABCP, com massa específica de $3,15 \mathrm{~g} \mathrm{~cm}^{-3} \mathrm{e}$ área específica de $0,354 \mathrm{~m}^{2} \mathrm{~g}^{-1}$, sendo os resultados a média de três determinações, com desvio-padrão máximo de $2 \%$.

Consumo de Cal: As amostras de material pozolânico foram submetidas ao ensaio de consumo de cal, para determinação de sua atividade pozolânica, segundo o método Chapelle (Raverdy et al., 1980) modificado, cujos resultados foram expressos em mg CaO g${ }^{-1}$ amostra.

Índice de Atividade Pozolânica com Cal: A atividade pozolânica das amostras de material pozolânico foi determinada através do índice de atividade pozolânica com cal, de acordo com a Norma NBR - 5751 (ABNT, 1992) sendo os resultados apresentados em MPa.

Para a realização dos ensaios mecânicos, foram preparadas argamassas de cal pozolânica no traço 1:3 (uma parte de aglomerante, cal pozolânica e três partes de areia normal) e fator água/aglomerante determinado através dos ensaios de consistência normal, segundo a Norma NBR - 9290 (ABNT, 1986). Foram estudadas três composições de cal pozolânica: $30 \%$ de cal e $70 \%$ de material pozolânico, $40 \%$ de cal e $60 \%$ de material pozolânico e 50\% de cal e 50\% de material pozolânico (Lima, 1993).

Os corpos de prova foram moldados utilizando-se moldes cilíndricos com dimensões de $5 \times 10 \mathrm{~cm}$ (diâmetro, altura) conforme recomenda a Norma NBR - 7215 (ABNT, 1991). A cura dos corpos de prova se deu durante os períodos de 7, 28 e 60 dias, tendo sido utilizados dois tipos de cura: a cura aérea e a cura imersa em água. A cura aérea foi realizada de forma que os corpos de prova ficassem expostos ao ar e umedecidos a partir do quinto dia, até que se completassem os sete primeiros dias de cura, enquanto a cura imersa em água foi realizada em um reservatório contendo água e $2 \% \mathrm{de}$ cal, onde os corpos de prova foram submersos a partir do oitavo dia de cura (Vorobiev, 1965). Após completada a cura, os corpos de prova foram retirados do reservatório e submetidos aos ensaios de resistência a compressão simples (RCS), segundo a Norma NBR - 7215 (ABNT, 1991) sendo os resultados apresentados em MPa.

\section{RESULTADOS E DISCUSSÃO}

\section{Análise química}

As composições químicas das amostras de material pozolânico são apresentadas na Tabela 1. As amostras Entulho 1, Entulho 2, Mistura e Pozolana, apresentaram a soma dos percentuais de $\mathrm{Si}_{2} \mathrm{O}, \mathrm{Fe}_{2} \mathrm{O}_{3}$ e $\mathrm{Al}_{2} \mathrm{O}_{3}$, de $87,07 \%, 82,72 \%, 92,88 \%$ e $96,73 \%$, respectivamente, cujos valores superam o valor mínimo de 70\% (ASTM, 1998). O percentual de MgO também satisfaz o valor máximo de $5 \%$ exigido; assim, estas amostras atendem às especificações químicas exigidas pela ASTM para que uma amostra seja considerada material pozolânico. As amostras de entulho (Entulho 1 e Entulho 2) e a amostra Mistura, podem ser classificadas como sílico-aluminosas, quanto à composição química, exceção feita à amostra Pozolana, que pode ser classificada como uma amostra predominantemente silicosa. $\mathrm{O}$ teor de sílica $\left(\mathrm{SiO}_{2}\right)$ apresentado pelas amostras é considerado elevado, fato desejável em materiais ativos e que tem papel importante, pois ao longo do tempo tem-se reações que formam os silicatos e aluminatos de cálcio hidratados, responsáveis pela resistência mecânica desenvolvida.

Tabela 1. Composição química das amostras de material pozolânico

\begin{tabular}{crrrc}
\hline Determinações (\%) & Entulho 1 & Entulho 2 & Mistura & Pozolana \\
\hline Perda ao Rubro (PR) & 8,53 & 9,52 & 2,37 & 3,03 \\
$\mathrm{SiO}_{2}$ & 58,09 & 62,92 & 58,58 & 80,00 \\
$\mathrm{Fe}_{2} \mathrm{O}_{3}$ & 5,30 & 3,75 & 8,20 & 0,72 \\
$\mathrm{Al}_{2} \mathrm{O}_{3}$ & 23,68 & 16,05 & 26,10 & 16,01 \\
$\mathrm{CaO}$ & 1,40 & Nihil & Nihil & Nihil \\
$\mathrm{MgO}$ & Traços & 2,18 & Traços & Traços \\
$\mathrm{Na}_{2} \mathrm{O}$ & 0,57 & 0,68 & 1,22 & Traços \\
$\mathrm{K}_{2} \mathrm{O}$ & 2,42 & 3,03 & 3,03 & Traços \\
\hline
\end{tabular}

As composições químicas das amostras de cal são apresentadas na Tabela 2. Segundo a Norma NBR - 6453 (ABNT, 1988) a cal Carbomil pode ser classificada como cal cálcica, por apresentar percentagem de $\mathrm{CaO}$, em relação ao óxidos totais, maior que $90 \%(94,04 \%)$ e a cal Megaó pode ser classificada como cal dolomítica, por apresentar percentagem de $\mathrm{CaO}$, em relação aos óxidos totais, menor que $65 \%(57,30 \%)$.

Tabela 2. Composição química das amostras de cal

\begin{tabular}{ccc}
\hline Determinações (\%) & Carbomil & Megaó \\
\hline Perda ao Rubro (PR) & 25,39 & 24,94 \\
$\mathrm{SiO}_{2}$ & 0,37 & 3,36 \\
$\mathrm{Fe}_{2} \mathrm{O}_{3}$ & Traços & Traços \\
$\mathrm{Al}_{2} \mathrm{O}_{3}$ & Traços & Traços \\
$\mathrm{CaO}$ & 69,44 & 42,92 \\
$\mathrm{MgO}$ & 4,03 & 28,62 \\
$\mathrm{Na}_{2} \mathrm{O}$ & Traços & Traços \\
$\mathrm{K}_{2} \mathrm{O}$ & Traços & Traços \\
Óxidos & 98,47 & 95,31 \\
\hline
\end{tabular}

* Cálculo mediante a Norma NBR - 7175 (ABNT, 1992)

A especificação brasileira NBR-7175 (ABNT, 1992) estabelece, como critério de qualidade (pureza da cal) o teor mínimo de $88 \%$ de óxidos totais; segundo este critério, pode-se afirmar que as amostras de cal aqui analisadas, são consideradas de elevada pureza, com teores de $98,47 \%$ para a cal Carbomil e de 95,31\% para a cal Megaó. 


\section{Análise térmica diferencial (ATD)}

Os termogramas (Figura 1) indicaram que as amostras de material pozolânico e cal apresentam as seguintes composições mineralógicas: a amostra Entulho 1 apresenta pico endotérmico a $142^{\circ} \mathrm{C}$, característico da perda de água adsorvida, e a $581{ }^{\circ} \mathrm{C}$ um pico, também endotérmico, característico da transformação de quartzo $\alpha$ em $\beta$. A amostra Entulho 2 mostra os picos endotérmicos: a $127^{\circ} \mathrm{C}$ referente à perda de água adsorvida; a $565{ }^{\circ} \mathrm{C}$ correspondente à desidroxilação da portlandita $\left(\mathrm{Ca}(\mathrm{OH})_{2}\right) ;$ a $578^{\circ} \mathrm{C}$ indicando a transformação de quartzo $\alpha \mathrm{em}$ $\beta$; a $871{ }^{\circ} \mathrm{C}$, referente à decomposição da calcita $\left(\mathrm{CaCO}_{3}\right)$ e a $917^{\circ} \mathrm{C}$ discreto pico exotérmico, indicando a nucleação da mulita $\left(3 \mathrm{Al}_{2} \mathrm{O}_{3} \cdot 2 \mathrm{SiO}_{2}\right)$. A amostra Mistura apresenta picos endotérmicos: a $117^{\circ} \mathrm{C}$ referente à perda de água adsorvida; a $579^{\circ} \mathrm{C}$, indicando a transformação de quartzo $\alpha \mathrm{em} \beta$ e a $908^{\circ} \mathrm{C}$ mostra uma pequena banda exotérmica característica da nucleação de mulita. A amostra Pozolana apresenta os picos endotérmicos: a $112{ }^{\circ} \mathrm{C}$ característico da perda de água adsorvida; a $570{ }^{\circ} \mathrm{C}$ indicando a transformação de quartzo $\alpha$ em $\beta$; a $579{ }^{\circ} \mathrm{C}$, característico da perda de hidroxilas da camada octaédrica e a $984^{\circ} \mathrm{C}$, um grande pico exotérmico característico da nucleação de mulita. A amostra de cal Carbomil apresenta os picos endotérmicos: a $117{ }^{\circ} \mathrm{C}$ característico da perda de água adsorvida; a $393{ }^{\circ} \mathrm{C}$ referente à desidroxilação da brucita $\left(\mathrm{Mg}(\mathrm{OH})_{2}\right)$; a $570{ }^{\circ} \mathrm{C}$, característico da desidroxilação da portlandita e a $871{ }^{\circ} \mathrm{C}$, referente à decomposição da calcita. A cal Megaó apresenta os picos endotérmicos: a $117{ }^{\circ} \mathrm{C}$ característico da perda de água adsorvida; a $414{ }^{\circ} \mathrm{C}$ referente à desidroxilação da brucita $\left(\mathrm{Mg}(\mathrm{OH})_{2}\right)$; a $565{ }^{\circ} \mathrm{C}$, característico da desidroxilação da portlandita e a $915^{\circ} \mathrm{C}$ referente à decomposição da calcita.

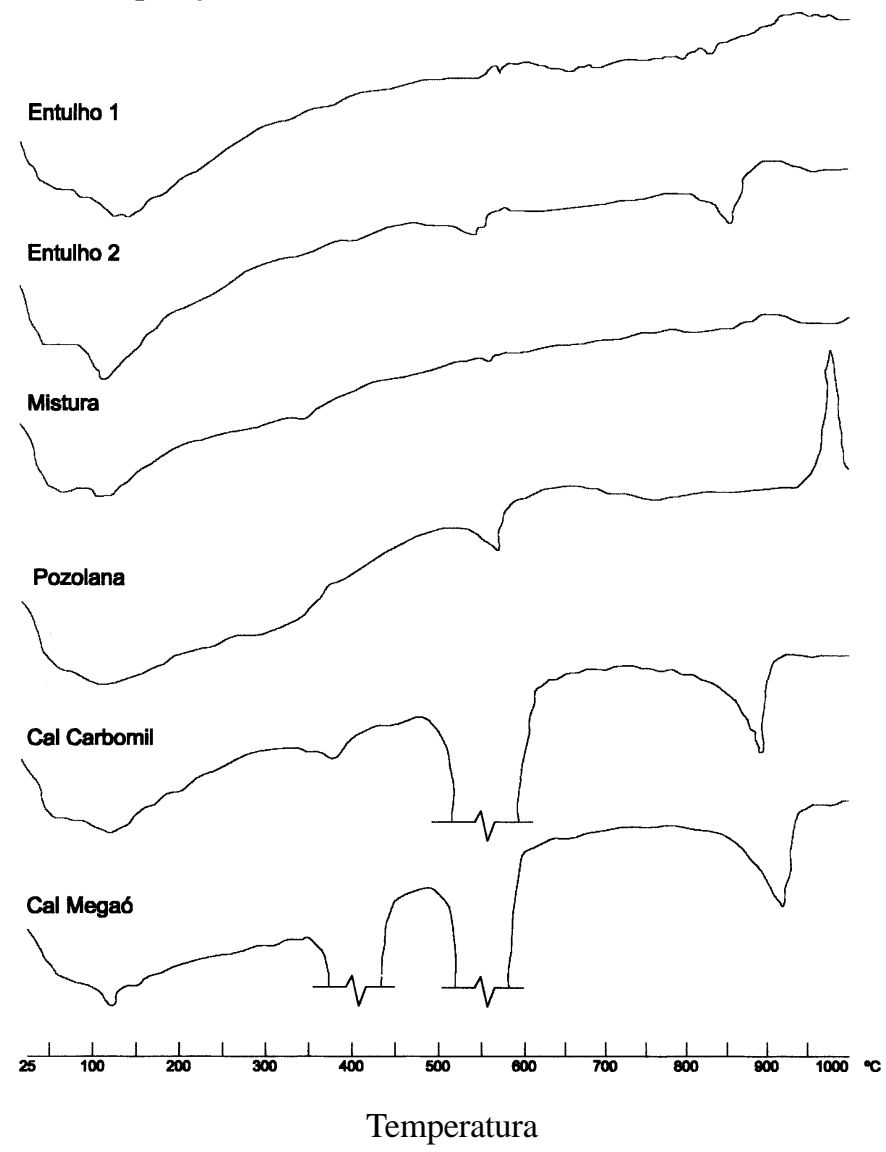

Figura 1. Termogramas das amostras de material pozolânico e cal

\section{Difração de raios-X}

Os difratogramas (Figura 2) indicaram que as amostras de material pozolânico e cal apresentam as seguintes composições mineralógicas: a amostra Entulho 1 é composta por quartzo (3,34, 1,81 e 4,21) e calcita $\left(\mathrm{CaCO}_{3}\right)(3,03,1,90$ e 1,87); a amostra Entulho 2 é composta por quartzo $\left(4,20,3,34 \mathrm{e} \mathrm{1,81)}, \mathrm{CaCO}_{3}(3,03,1,91 \mathrm{e}\right.$ $1,87)$ e mulita $\left(3 \mathrm{Al}_{2} \mathrm{O}_{3} \cdot 2 \mathrm{SiO}_{2}\right)(3,46,2,23$ e 1,53$)$ e a Mistura se compõe de quartzo $\left(3,34,1,81\right.$ e 4,24), hematita $\left(\mathrm{Fe}_{2} \mathrm{O}_{3}\right)(2,69,2,51$ e 1,69$)$ e mulita $(3,46,2,20$ e 1,53$)$ enquanto na amostra Pozolana são observados a presença de caulinita $(7,15,3,52$ e 2,36), em pequena quantidade, quartzo $(4,25,3,34$ e 1,81$)$ e uma discreta banda de amorfização $\left(18^{\circ}<2 \theta<30^{\circ}\right)$ característica da metacaulinita $2\left(\mathrm{Al}_{2} \mathrm{O}_{3} \cdot 2 \mathrm{SiO}_{2}\right)$. A cal Carbomil é composta por $\mathrm{CaCO}_{3}\left(3,03,1,92 \mathrm{e}^{2} 1,87\right)$, magnesita $\left(\mathrm{MgCO}_{3}\right)(2,74,2,10 \mathrm{e} 1,68) \mathrm{e}$ $\mathrm{MgO}(2,10,1,48$ e 1,20$)$ e a cal Megaó, por brucita $\mathrm{Mg}(\mathrm{OH})_{2}$ $(4,77,2,37 \mathrm{e} 1,18)$ e $\mathrm{MgO}(2,10,1,49 \mathrm{e} 1,20)$.

Dos resultados apresentados acima pela caracterização mineralógica, adotou-se a cal Carbomil como amostra única para o desenvolvimento das demais etapas deste estudo, escolha baseada no teor de $\mathrm{MgO}$ que, na cal Megaó, apresenta-se em elevada quantidade, resultando numa hidratação mais lenta, ocorrendo simultaneamente à carbonatação; assim, a etapa de hidratação pode se dar de forma retardada, após a aplicação, causando aumento de volume, que compromete a argamassa, através do surgimento de fissuras e desagregações (Guimarães \& Cincotto, 1985).

\section{Área específica}

$\mathrm{Na}$ Tabela 3 são apresentados os valores de áreas específicas, determinados pelo método do Permeâmetro de Blaine, das amostras de material pozolânico e das amostras de cal. A amostra Pozolana foi a que apresentou maior área específica, seguida pelas amostras Mistura, Entulho 2 e Entulho 1.

A cal Carbomil apresentou área específica de $1,222 \mathrm{~m}^{2} \mathrm{~g}^{-1}$, enquanto a cal Megaó apresentou maior área específica, comparada com a anterior, de $1,738 \mathrm{~m}^{2} \mathrm{~g}^{-1} \mathrm{e}$, em virtude de sua maior superfície de contato é, provavelmente, a mais reativa; contudo, embora a área específica de uma cal seja um dos fatores mais importantes entre suas propriedades físicas, como material de construção, não pode ser tomada como critério único de seleção e qualidade, como foi visto nos itens de caracterização mineralógica.

\section{Consumo de cal}

Na Tabela 4 tem-se os resultados obtidos para os ensaios de consumo de cal das amostras de material pozolânico, através dos quais se observa que a amostra Pozolana, considerada padrão, apresenta maior consumo de cal, indicando ser esta amostra a de maior capacidade de fixação de cal, ou seja, capacidade de reagir com cal, formando compostos com propriedades cimentícias. Dos materiais reciclados, a amostra Mistura apresenta maior consumo de cal, devido à presença dos materiais cerâmicos que, quando moídos, exibem a propriedade de reagir com cal; nas amostras Entulho 1 e Entulho 2 observaram-se valores inferiores, o que se justifica por serem estas amostras derivadas de misturas de diversos componentes, entre eles materiais inertes à cal. Embora os materiais reciclados tenham apresentado menores valores representativos do consumo de cal, não implica dizer que estas amostras não apresentam propriedades pozolânicas e, sim, propriedades pozolânicas em menor intensidade. 

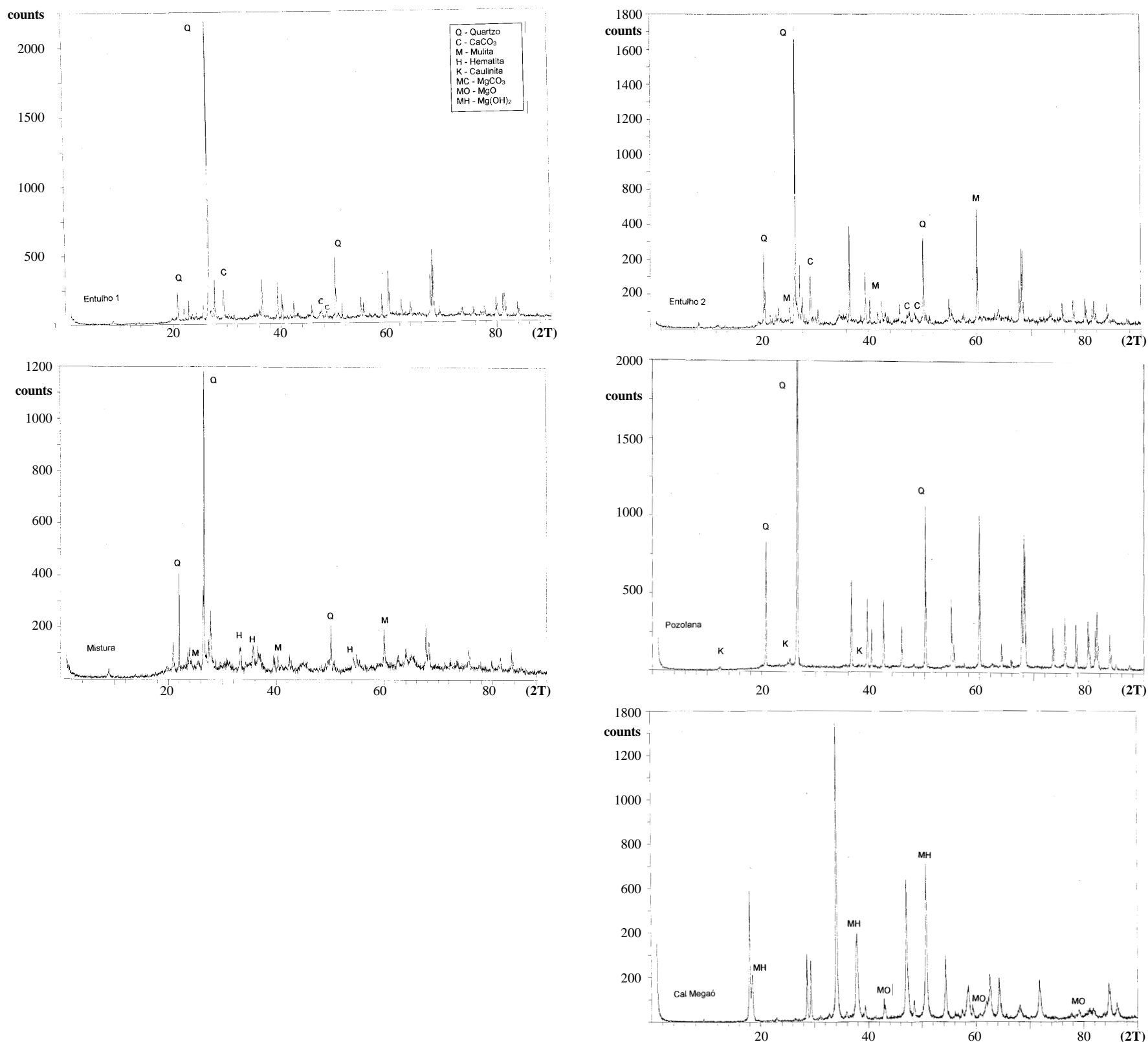

Figura 2. Difratogramas das amostras de material pozolânico e cal

Tabela 3. Áreas específicas das amostras de material pozolânico e das amostras de cal, pelo método de permeâmtro de Blaine

\begin{tabular}{lc}
\hline Amostras & Áreas Específicas $\left(\mathrm{m}^{2} \mathrm{~g}^{-1}\right)$ \\
\hline Entulho 1 & 0,220 \\
Entulho 2 & 0,239 \\
Mistura & 0,340 \\
Pozolana & 0,638 \\
Cal Carbomil & 1,222 \\
Cal Megaó & 1,738 \\
\hline
\end{tabular}

Tabela 4. Consumo de cal das amostras de material pozolânico

\begin{tabular}{lc}
\hline Amostras & Consumos de Cal (mg CaO g \\
\hline Entulho 1 & 124,7 \\
Entulho 2 & 95,6 \\
Mistura & 171,3 \\
\hline
\end{tabular}

\section{Índice de atividade pozolânica com cal}

Os valores do índice de atividade pozolânica com cal, encontrados para as amostras de material pozolânico, estão apresentados na Tabela 5. Uma análise dos resultados mostra que o comportamento apresentado pelas amostras foi similar ao ensaio do consumo de cal, mostrado anteriormente, com a amostra Pozolana, apresentando maior grau de pozolanicidade, e a amostra Mistura como a mais reativa entre os materiais reciclados.

Segundo a Norma NBR - 5751 (ABNT, 1992) a Pozolana pode ser considerada material pozolânico, por apresentar resistência igual ou superior a 5,5 MPa. A Mistura, embora tenha apresentado valor de 5,21 MPa, encontra-se bastante próximo do valor de referência podendo ser, também, classificada como material pozolânico, com propriedades aglomerantes.

\section{Resistência à compressão simples (RCS)}

Nas Figuras 3A, 3B e 3C são apresentados os resultados de RCS das argamassas com Entulho 1 e Entulho 2, Mistura e 
Pozolana, curadas por períodos de 7, 28 e 60 dias, nas composições de $30-70 \%$, 40-60\% e 50-50\% de cal e pozolana, respectivamente.

Tabela 5. Índice de atividade pozolânica com cal para as amostras de material pozolânico

\begin{tabular}{lc}
\hline Amostras & Índices de Atividade Pozolânica com Cal (MPa) \\
\hline Entulho 1 & 2,41 \\
Entulho 2 & 1,91 \\
Mistura & 5,21 \\
Pozolana & 6,51 \\
\hline
\end{tabular}

Analisando-se a Figura 3A na qual estão representados os valores de RCS obtidos com as argamassas de cal pozolânica na composição $30-70 \%$ de cal e pozolana, verifica-se que as argamassas com Pozolana apresentam melhor comportamento mecânico, frente às demais. Das amostras de material reciclado, as argamassas com Mistura se sobressaem, apresentando valor máximo de RCS de 5,13 MPa, aos 60 dias de cura, bastante próximo do apresentado pela argamassa com Pozolana $(5,99$ $\mathrm{MPa}$ ). As argamassas com as amostras de entulho (Entulho $1 \mathrm{e}$ Entulho 2) apresentam comportamento mecânico bastante similar.

Nas Figuras 3B e 3C nas quais estão representados os valores de RCS obtidos com as argamassas de cal pozolânica nas composições de $40-60 \%$ e de $50-50 \%$ de cal e pozolana, observa-se o mesmo comportamento verificado na Figura 3(A). Observa-se ainda nítida evolução, a medida em que avança a idade de cura, nos valores representativos de RCS nas argamassas com Mistura, chegando a atingir valores muito próximos (Figura 3B) e até mesmo superiores (Figura 3C) aos oferecidos pelas argamassas com Pozolana. Os valores máximos obtidos aos 60 dias de cura, com as argamassas com Mistura e Pozolana, foram de: 4,51 MPa (40 - 60\% de cal e pozolana) e 3,77 $\mathrm{MPa}(50-50 \%$ de cal e pozolana) e de 4,62 MPa (40 - 60\% de cal e pozolana) e 3,64 MPa (50 - 50\% de cal e pozolana) respectivamente.

Os resultados de RCS obtidos para as argamassas com Entulho 1 e Entulho 2 apresentam-se inferiores aos obtidos para as demais argamassas, em virtude da heterogeneidade das amostras de entulho, que apresentam, em sua composição, tanto materiais reativos como materiais inertes, que não participam das reações originárias dos compostos com poder aglomerante.

De acordo com os resultados obtidos das três composições de cal pozolânica estudadas, a que apresenta melhores resultados de RCS é a 30-70\% de cal e pozolana. Observa-se, ainda, que são necessárias idades de cura prolongadas (60 dias) pois as reações entre a cal e o material pozolânico, que formam compostos de propriedades cimentícias, e que, por sua vez, conferem às argamassas desempenho mecânico satisfatório, são bastante lentas.

Relacionando-se os resultados de RCS com os obtidos para os ensaios de consumo de cal e índice de atividade pozolânica com cal, observa-se que as amostras Mistura e Pozolana caracterizam-se por apresentarem maiores valores representativos do grau de pozolanicidade, e também maiores valores de RCS; esses resultados confirmam que, quanto maior a atividade pozolânica de uma amostra, maiores as propriedades mecânicas conferidas às argamassas.
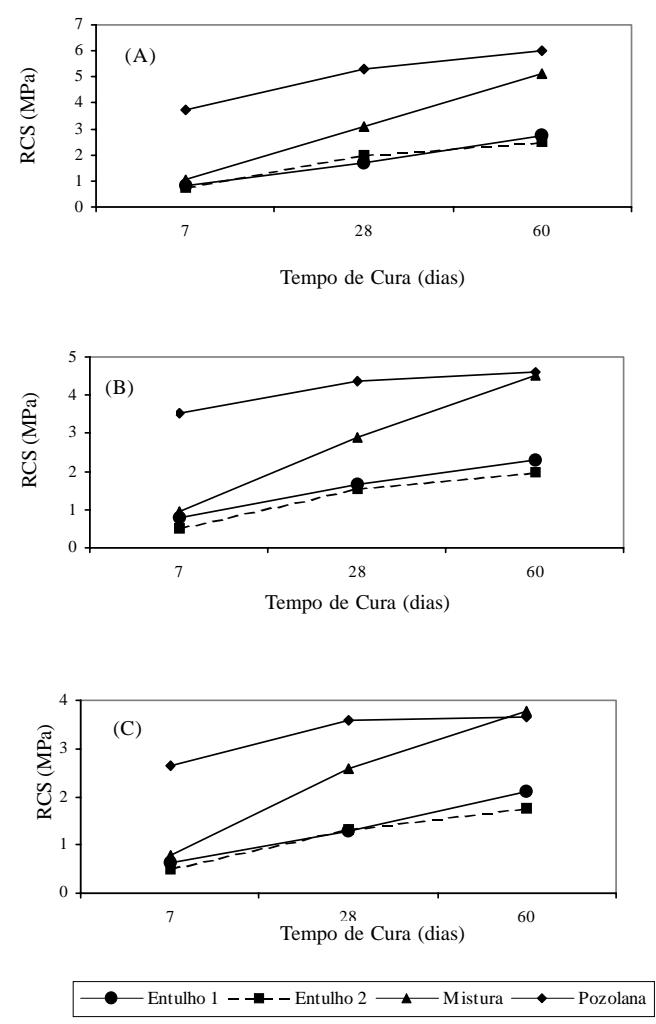

Figura 3. Resistência à Compressão Simples (RCS) em função do tempo de cura para as argamassas com Entulho 1, com Entulho 2, com Mistura e com Pozolana, nas diferentes composições de cal e pozolana. (A) $30-70 \%$, (B) $40-60 \%$ e (C) 50-50\%.

Comparando-se os resultados de RCS obtidos para as argamassas estudadas aos 28 dias de cura, com a especificação da Norma NBR - 13281 (ABNT, 1995) estas podem ser classificadas como argamassas do Tipo I, por atenderem ao limite de resistência entre $0,1 \mathrm{MPa}$ e 4,0 $\mathrm{MPa}$.

Uma análise conjunta dos resultados revela que as amostras de entulho e resíduos cerâmicos reciclados apresentam boas características mineralógicas e atividade pozolânica, assim como as argamassas alternativas preparadas com essas amostras e com cal hidratada, apresentam desempenho mecânico satisfatório. Outra constatação importante é que a reciclagem de entulho ou resíduos gerados pela indústria da construção civil é bastante promissora, podendo gerar elementos de baixo custo, destinados a obras civis e, mais que isto, seu aproveitamento implica na preservação do meio ambiente e na melhoria da qualidade de vida da população em geral.

\section{CONCLUSÕES}

Com o objetivo de reciclar entulhos e resíduos cerâmicos oriundos da construção civil para uso como agente pozolânico, em argamassas alternativas de cal pozolânica, concluiu-se que:

1. As amostras Entulho 1, Entulho 2 e Mistura podem ser classificadas como sílico-alumiosas, e a amostra Pozolana como predominantemente silicosa.

2. A cal Carbomil pode ser classificada como cálcica e a Megaó como dolomítica.

3. A amostra Entulho 1 é composta mineralogicamente por quartzo e calcita; a amostra Entulho 2 por portlandita, quartzo, 
calcita e mulita; a amostra Mistura por quartzo, hematita e mulita, e a Pozolana por quartzo, caulinita e mulita.

4. A cal Carbomil é composta mineralogicamente por brucita, portlandita, calcita, magnesita e óxido de magnésio, e a cal Megaó por brucita, portlandita, calcita e óxido de magnésio.

5. A Pozolana é a amostra com maior atividade pozolânica, e a Mistura é a mais reativa entre os materiais reciclados.

6. As argamassas alternativas apresentam desempenho mecânico satisfatório, sendo a reciclagem de resíduos bastante promissora, capaz de produzir elementos construtivos de baixo custo, além de preservar o meio ambiente, melhorando a qualidade de vida da população em geral.

\section{REFERÊNCIAS BIBLIOGRÁFICAS}

ABNT (Rio de Janeiro, RJ). NBR - 7214, Areia normal para ensaio de cimento, 1982.

ABNT (Rio de Janeiro, RJ). NBR - 9290, Cal hidratada para argamassas - Determinação da retenção de água, 1986.

ABNT (Rio de Janeiro, RJ). NBR - 6453, Cal virgem para construção, 1988.

ABNT (Rio de Janeiro, RJ). NBR - 7215, Cimento Portland Determinação da resistência à compressão, 1991.

ABNT (Rio de Janeiro, RJ). NBR - 5751, Materiais Pozolânicos -Determinação de atividade pozolânica-Índice de atividade pozolânica com cal, 1992.

ABNT (Rio de Janeiro, RJ). NBR - 7175, Cal hidratada para argamassas, 1992.

ABNT (Rio de Janeiro, RJ). NBR - 7224, Cimento Portland e outros materiais em pó - Determinação da área específica, 1994.

ABNT (Rio de Janeiro, RJ). NBR - 13281, Argamassa industrializada para assentamento de paredes $\mathrm{e}$ revestimento de paredes e tetos, 1995.

ANÔNIMO. Métodos de análise química de argilas e pozolanas, Campina Grande: LAM/DMG/CCT/UFPB, 1994.

ASTM, American Society for Testing and Materials Standard specification for coal fly ash and raw of calcined natural pozzolans for use as mineral admixtures in concrete, C-618, 1998.
CINCOTTO, M.A. Utilização de subprodutos e resíduos na indústria da construção civil, Tecnologia de Edificações, São Paulo, 1983, p. 71-78.

COELHO, P.E.; CHAVES A.P. Reciclagem de entulho - Uma opção de negócio potencialmente lucrativa e ambientalmente simpática. Areia e Brita, São Paulo, v. 2, n. 5, p. 31-35, 1998.

GUIMARÃES, J.E.P.; CINCOTTO, M.A. A cal nas construções civis - Na patologia das argamassas, 1. ed. São Paulo: Associação Brasileira dos Produtores de Cal, 1985. 85p.

LEVY, S.M.; HELENE, P.R.L. Reciclagem de entulhos na construção civil, a solução política e ecologicamente correta. In: SIMPÓSIO BRASILEIRO DE TECNOLOGIA DAS ARGAMASSAS, 1., Goiânia, 1995, Anais... p. 315-325, Goiânia.

LEVY, S.M.; MARTINELLI, F.A.; HELENE, P.R L. A influência de argamassas endurecidas e resíduos cerâmicos, finamente moídos, nas propriedades de novas argamassas. In: SIMPÓSIO BRASILEIRO DE TECNOLOGIA DAS ARGAMASSAS, 2., Salvador, 1997, Anais... p. 50-63, Salvador.

LIMA, J.B.M. Cais pozolânicas, caracterização e desempenho mecânico. Campina Grande: UFPB, 1993. 127p. Dissertação Mestrado

PATRÍCIO, S.M.R.; MORAIS, C.R.S.; NEVES, G.A.; BRASILEIRO, F.E.; PEREIRA, E.C. Aproveitamento dos resíduos na construção civil para uso como agregados em argamassas. Campina Grande: UFPB, 1997. 35p. Relatório Projeto PATME - SEBRAE

PINTO, P.T. Resultados da gestão diferenciada, Téchne, São Paulo, n. 5, p. 31-34, nov/dez. 1997.

RAVERDY, M.; BRIVOT, F.; PAILLÉRE, A.M.; DRON, R. Appréciaciton de l'activité pouzzolanique des constituants secondaires. In: CONGRÉS INTERNATIONAL DE LA CHIMIE DES CIMENTS, 7., Paris, Anais... 1980. p. 30. Paris.

SILVA, A.S.R.; SILVA FILHO, A.F.; AZEVEDO, M.T.; MATTOS, E.G. Argamassa inorgânica com o emprego de entulho reciclado. In: SIMPÓSIO BRASILEIRO DE TECNOLOGIA DAS ARGAMASSAS, 2., Salvador, 1997, Anais... p. 203-207, Salvador.

SINGER, F; SINGER, S. Industrial ceramics, London: Chapman \& Hall Ltda., 1971, p.678-679. Cap. 7.

VILLARI, A.C. Transformar entulho em material útil reduz o custo da construção, O Estado de São Paulo, São Paulo, Caderno de Negócios e Oportunidades, p. 1, 18 de out. 1992.

VOROBIEV, V.A. Building materials. Moscow: Higher School Publishing House, 1965. 112p. 